\title{
Long-term observations of the urban mixing-layer height with ceilometers
}

\author{
S Emeis ${ }^{1,3}$, K Schäfer ${ }^{1}$, C Münkel $^{2}$ \\ ${ }^{1}$ Institut für Meteorologie und Klimaforschung - Atmosphärische Umweltforschung, \\ Forschungszentrum Karlsruhe, Garmisch-Partenkirchen, Germany \\ ${ }^{2}$ Vaisala GmbH, Hamburg, Germany \\ stefan.emeis@imk.fzk.de
}

\begin{abstract}
Urban air quality assessment requires the knowledge of the temporal and spatial structure of the mixing-layer height (MLH), because this variable controls the vertical space for rapid mixing of near-surface pollutants. Because MLH is a consequence of vertical temperature and moisture profiles in the lower atmosphere, remote sensing is a suitable tool to monitor MLH. Two ceilometers, a Vaisala LD40 and a Vaisala CL31, have been run for many months in the German city of Augsburg to observe the vertical aerosol distribution. Wind and temperature profile information have been obtained for the same period from sodar observations. This paper compares the MLH determined from the optical backscatter intensity received by the two ceilometers among each other and with the MLH derived from the acoustic backscatter intensity and the variance of the vertical wind component from sodar measurements.
\end{abstract}

\section{Introduction}

The mixing layer height (MLH) is assumed to be a key parameter for the characterisation of air pollution, because this variable controls the vertical space for rapid mixing of near-surface pollutants. The determination and modelling of the MLH has therefore found considerable interest in the recent decade [1], especially in urban meteorology. With today's availability of ground-based remote sensing devices for monitoring the structure of the atmospheric boundary layer (ABL) it has been shown that the ABL sometimes exhibits multiple layering (e.g. internal boundary layers, near-surface inversions and residual layers at night-time and in the morning hours)[2]. It was demonstrated that the lowest stable layer or inversion limits the vertical exchange of primary pollutants emitted at or near the surface [3] and thus controls the near-surface pollutant concentrations. Acoustic remote sensing has also been used to derive climatologic statistics of MLH for towns ([4], [5]) and wind and turbulence profiles over towns [6]. Multiple inversions within a few hundred meters above ground have been detected both with optical and acoustic remote sensing in an Alpine valley [7]. MLH information is also necessary for special kinds of satellite data interpretation, e. g. the retrievals of optical depths for the particle concentration near the surface [8].

\footnotetext{
${ }^{3}$ To whom any correspondence should be addressed
} 
MLH is supposed to vary on the regional scale due to the weather conditions with smaller variations due to land surface properties types. Therefore it is interesting to analyze whether a town like Augsburg (about 265000 inhabitants in 2007) influences and modifies MLH. Augsburg is situated about $60 \mathrm{~km}$ west-north-west of Munich in a rural area on the river Lech. The Lech is flowing north from the Alps (about $100 \mathrm{~km}$ south of Augsburg) towards the Danube in a shallow valley, which is about $10 \mathrm{~km}$ wide and about $100 \mathrm{~m}$ deep. Under synoptically calm conditions with weak pressure gradients we observe light winds from the south at night and from the north to north east at daytime. At the presence of stronger pressure gradients the winds do not deviate much from the large-scale synoptic winds. Prevailing wind direction of such cases is from the south west.

For the investigation two ceilometers were placed at the northern edge of the town, in the town centre, and the sodar at the southern edge of the town. The investigation is complicated by the fact that two different ceilometers have been used in this measurement experiment. Therefore, in a comparison experiment, all three remote sensing instruments have been situated side by side for four weeks. The enhancement of the methodology for the determination of MLH from an integration of these different remote sensing methods is a further objective of this experiment.

The paper presents results and conclusions from this intercomparison exercise.

\section{Methodology}

In the following subsections we will describe the algorithms with which the MLH is derived from ground-based remote sensing data. We will denote with the letter $\mathrm{H}$ and an attached number certain derived heights which are related to inversions and the MLH; while we will use the variable $\mathrm{z}$ to denote the normal vertical coordinate.

\subsection{Acoustic detection of MLH}

Beyrich [9] has listed possible ways to analyze MLH from acoustic backscatter intensities measured by a sodar. This algorithm has been enhanced in [4] by simultaneously using acoustic backscatter intensity and the variance of the vertical velocity component $\sigma_{w}$. In [7] the algorithm has been extended for the detection of multiple inversions present simultaneously. The algorithm determines (Figure 1):

- the height of a turbulent layer (H1) characterised by high acoustic backscatter intensities $\mathrm{R}(\mathrm{z})$ due to thermal fluctuations (thus having a high $\sigma_{\mathrm{w}}$ ),

- several lifted inversions (H2_n) characterized by secondary maxima of acoustic backscatter due to a sharp increase of temperature with height and simultaneously low $\sigma_{\mathrm{w}}$, and

- the height of a surface-based stable layer (H3) characterised by high backscatter intensities due to a large mean vertical temperature gradient starting directly at the ground and having a low $\sigma_{\mathrm{w}}$.

The mixing layer height (MLH) is defined as the minimum of the heights H1, the lowest H2 (i.e. $\mathrm{H} 2 \_1$ ), and H3. Acoustic remote sensing by a SODAR also yields wind fields that in principle could be used for determination of the mixing layer height, too. Because the wind information above the inversion is not regularly available from SODAR measurements, wind data have not been included into the scheme for the determination of the mixing layer height.

The height $\mathrm{H} 1$ corresponds to a sharp decrease of the acoustic backscatter intensity R(z) with height $\mathrm{z}$ usually indicating the top of a turbulent layer:

$$
\mathrm{H} 1=\mathrm{z} \text {, if }\left(\mathrm{R}(\mathrm{z})<88 \mathrm{~dB} \text { and } \mathrm{R}\left(\mathrm{z}^{+} 1\right)<86 \mathrm{~dB} \text { and } \mathrm{R}\left(\mathrm{z}^{+}+2\right)<84 \mathrm{~dB}\right) .
$$

The $\mathrm{dB}$ values are derived from an arbitrary scale because the received acoustic backscatter intensities from a SODAR cannot be calibrated. Therefore, the $\mathrm{R}(\mathrm{z})$ values are specific for the type of SODAR used. Therefore, the numbers in (1) can be taken for illustration purposes only. 
Elevated inversions are diagnosed from secondary maxima of the backscatter intensity that are not related to high turbulence intensities. For elevated inversions an increase in backscatter intensity below a certain height $\mathrm{z}=\mathrm{H} 2$ and a decrease above is stipulated while the turbulence intensity is low:

$$
\mathrm{H} 2 \_\mathrm{n}=\mathrm{z} \text {, if }\left(\partial \mathrm{R} /\left.\partial \mathrm{z}\right|_{\mathrm{z}+1}<0 \text { and } \partial \mathrm{R} /\left.\partial \mathrm{z}\right|_{\mathrm{z}-1}>0 \text { and } \sigma_{\mathrm{w}}<0.70 \mathrm{~ms}^{-1}\right)
$$

for $\mathrm{n}=1, \ldots, \mathrm{N}$. In [7] $\mathrm{N}$ was chosen to be five. The determination of the height of the stable surface layer $\mathrm{H} 3$ is started if the backscatter intensity in the lowest range gates is above $105 \mathrm{~dB}$ while $\sigma_{\mathrm{w}}$ is smaller than $0.3 \mathrm{~ms}^{-1}$. The top of the stable layer $\mathrm{H} 3$ is at the height where either the backscatter intensity sinks below $105 \mathrm{~dB}$ or $\sigma_{\mathrm{w}}$ increases above $0.3 \mathrm{~ms}^{-1}$.

$$
\begin{array}{r}
\mathrm{H} 3=\mathrm{z}, \text { if }\left(\mathrm{R}(\mathrm{z})>105 \mathrm{~dB} \text { and } \mathrm{R}(\mathrm{z}+1)<105 \mathrm{~dB} \text { and } \sigma_{\mathrm{w}}(\mathrm{z})<0.3 \mathrm{~ms}^{-1}\right) \\
\quad \text { or if }\left(\sigma_{\mathrm{w}}(\mathrm{z})<0.3 \mathrm{~ms}^{-1} \text { and } \sigma_{\mathrm{w}}(\mathrm{z}+1)>0.3 \mathrm{~ms}^{-1} \text { and } \mathrm{R}(\mathrm{z})>105 \mathrm{~dB}\right)
\end{array}
$$

The $\mathrm{dB}$ values in (3) are given for the same illustrative purpose as in (1).

The search for $\mathrm{H} 2$ to $\mathrm{H} 3$ can be integrated into one search algorithm. If a surface-based stable layer with height $\mathrm{H} 3$ has been detected, the search for the first height $\mathrm{H} 2 \_1$ is started at the first range gate above $\mathrm{H} 3$, otherwise it starts at the lowest range gate. The search for elevated inversion is stopped when $\mathrm{N}$ elevated inversions have been found or the highest range gate of the available data has been reached.

The threshold values for $\sigma_{\mathrm{w}}$ used in (2) and (3) have been determined by optimizing the automatic application of the detection algorithm. In doing so it turned out that no lifted inversions occurred while the variance $\sigma_{\mathrm{w}}$ was lower than $0.7 \mathrm{~ms}^{-1}$. Thus this threshold made it possible to distinguish between inversions and elevated layers of enhanced turbulence. Further, the variance $\sigma_{\mathrm{w}}$ in nocturnal stable surface layers was always below $0.3 \mathrm{~ms}^{-1}$, so that this threshold made it possible to differentiate between nocturnal stable surface layers and daytime super-adiabatic surface layers although both types of surface layers yield more or less the same level of backscatter intensity. Finally MLH from the acoustic remote sensing is determined as the minimum of $\mathrm{H} 1, \mathrm{H} 2$ _ 1 , and $\mathrm{H} 3$ :

$$
\mathrm{MLH}_{\mathrm{ac}}=\min \left(\mathrm{H} 1, \mathrm{H} 2 \_1, \mathrm{H} 3\right)
$$

\subsection{Optical detection of MLH}

The heights of the near surface aerosol layers (H4_n) can be analysed from the optical vertical backscatter profiles. Here the gradient method is used. In this method the heights H4_n are characterized by minima of the vertical gradient (the term 'gradient minimum' is used here to denote the most negative value of the gradient, see also Fig. 1) of the optical attenuated backscatter intensity $(\mathrm{B}(\mathrm{z}))$. [10], [11] and [12] discussed the principle of the retrieval of this height. In [7] this approach has been refined and extended to enable the calculation of up to $n=5$ lifted inversions.

Prior to the determination of gradient minima the overlap and range corrected attenuated backscatter profiles have to be averaged over time and height to suppress noise generated artefacts (see also section 3.1). Therefore the $\mathrm{H} 4$ values are determined in a two-step procedure. Between 140 $\mathrm{m}$ and $500 \mathrm{~m}$ height sliding averaging is done over $15 \mathrm{~min}$ and a height interval $\Delta \mathrm{h}$ of $80 \mathrm{~m}$. In the layer between 500 and $2000 \mathrm{~m} \Delta \mathrm{h}$ for vertical averaging is extended to $160 \mathrm{~m}$. Two additional parameters have been introduced to further reduce the number of false hits. The minimum accepted attenuated backscatter intensity $B_{\min }$ right below a lifted inversion is set to $200^{*} 10^{-9} \mathrm{~m}^{-1} \mathrm{sr}^{-1}$ in the lower layer and $250^{*} 10^{-9} \mathrm{~m}^{-1} \mathrm{sr}^{-1}$ in the upper layer. Additionally the vertical gradient value $\partial \mathrm{B} / \partial \mathrm{z}_{\max }$ of a lifted inversion must be more negative than $-0.30 * 10^{-9} \mathrm{~m}^{-2} \mathrm{sr}^{-1}$ in the lower layer and more negative than $-0.30 * 10^{-9} \mathrm{~m}^{-2} \mathrm{sr}^{-1}$ in the upper layer. 
If $\mathrm{B}(\mathrm{z})$ denotes the measured attenuated backscatter intensity in the height $\mathrm{z}$ above ground averaged over time and height and $\Delta \mathrm{h}$ is the height averaging interval, then the gradient $\partial \mathrm{B} / \partial \mathrm{z}$ in the height $\mathrm{z}$ is calculated as

$$
\partial \mathrm{B} /\left.\partial \mathrm{z}\right|_{\mathrm{z}}=(\mathrm{B}(\mathrm{z}+\Delta \mathrm{h} / 2)-\mathrm{B}(\mathrm{z}-\Delta \mathrm{h} / 2)) / \Delta \mathrm{h}
$$

A gradient minimum is characterized by a change of sign from minus to plus of the second derivative of $\mathrm{B}(\mathrm{z})$. The height interval under examination is searched from bottom to top for these gradient minima $\mathrm{H} 4$ _n. The second derivative of $\mathrm{B}(\mathrm{z})$ in the height $\mathrm{z}$ is

$$
\partial^{2} \mathrm{~B} /\left.\partial \mathrm{z}^{2}\right|_{\mathrm{z}}=\left(\partial \mathrm{B} /\left.\partial \mathrm{z}\right|_{\mathrm{z}+\Delta \mathrm{h} / 2}-\partial \mathrm{B} /\left.\partial \mathrm{z}\right|_{\mathrm{z}-\Delta \mathrm{h} / 2}\right) / \Delta \mathrm{h}
$$

Thus $\mathrm{H} 4 \mathrm{n}$ is detected in a height $\mathrm{z}$ if the second derivative of $\mathrm{B}(\mathrm{z})$ one range gate below $\mathrm{z}$ is not positive, if the second derivative of $\mathrm{B}(\mathrm{z})$ in the height $\mathrm{z}$ is positive, and if the abovementioned false hit conditions are fulfilled:

$$
\begin{aligned}
& \mathrm{H} 4{ }_{-} \mathrm{n}=\mathrm{z} \text {, if } \partial^{2} \mathrm{~B} /\left.\partial \mathrm{z}^{2}\right|_{\mathrm{z}-1} \leq 0 \text { and } \partial^{2} \mathrm{~B} /\left.\partial \mathrm{z}^{2}\right|_{\mathrm{z}}>0 \text { and } \mathrm{B}(\mathrm{z}-\Delta \mathrm{h} / 2) \geq \mathrm{B}_{\min } \text { and } \partial \mathrm{B} /\left.\partial \mathrm{z}\right|_{\mathrm{z}} \leq \partial \mathrm{B} / \partial \mathrm{z}_{\max } \\
& \text { for } \mathrm{n}=1, \ldots, 5 \text {. }
\end{aligned}
$$

The MLH from optical remote sensing is taken as the lowest height H4 (see Figure 1):

$$
\mathrm{MLH}_{\mathrm{op}}=\mathrm{H}{ }_{-}{ }_{1}
$$

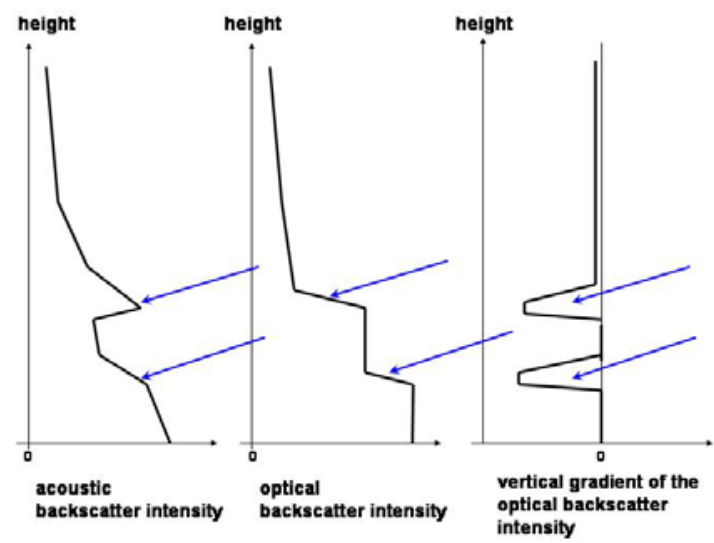

Figure 1. Schematic comparison of MLH determination algorithms in the case of a nocturnal stable surface layer and an elevated inversion above it. Left: vertical profile of acoustic backscatter intensity, middle: vertical profile of optical backscatter intensity, right: vertical profile of the vertical gradient of the optical backscatter intensity. Lower arrows mark the position of the height H3 (left) and H4_1 (middle and right). Upper arrows mark the heights H2_1 (left) and H4_2 (right). From [7].

The comparison between the two schemes for the determination of MLH from acoustic and optical backscatter intensities reveals an interesting difference which should be noted carefully (Figure 1): While we detect $\mathrm{H} 1$ and $\mathrm{H} 3$ from the acoustic backscatter intensity itself and $\mathrm{H} 2$ from the first derivative of this backscatter intensity, we need the first and the second derivative of the optical backscatter intensity (but not the optical backscatter intensity itself) to determine H4. This difference comes from unequal scattering processes for acoustic and optical waves: Acoustic waves are scattered at atmospheric refractivity gradients and thus at temperature gradients ([13]) while optical waves are scattered at small particles. Therefore the optical backscatter intensity is proportional to the aerosol concentration itself. The MLH on the other hand, which we desire to derive from these backscatter 
intensities, is in both cases found in heights where we have vertical gradients of the temperature and of the aerosol concentration. Therefore, in principle, the vertical distribution of the acoustic backscatter intensity should look very much alike the vertical distribution of the vertical gradient of the optical backscatter intensity.

The analysis of the sodar data and the ceilometer data can be combined to one single MLH information by forming the minimum from (4) and (8):

$$
\mathrm{MLH}=\min \left(\mathrm{MLH}_{\mathrm{ac}}, \mathrm{MLH}_{\mathrm{op}}\right)
$$

\section{Instrumentation}

\subsection{Ceilometer}

Two different ceilometers [10] have been used. One is a double-lens Vaisala LD40 (Figure 2, right) using infrared light with a wavelength of $855 \mathrm{~nm}$, a height resolution of $7.5 \mathrm{~m}$, and a maximum range of $13000 \mathrm{~m}$. The other is the one-lens CL31 (Figure 2, left) using infrared light of $910 \mathrm{~nm}$, a height resolution of $5 \mathrm{~m}$, and a maximum range of $7500 \mathrm{~m}$. The slightly different wavelengths and the unequal optical construction of both instruments lead to differences in the recorded optical backscatter intensities (see next section and Figure 4). Both ceilometers were sounding at zero zenith angles.

For both ceilometers averaging over $2 \mathrm{~min}$ and $60 \mathrm{~m}$ is not sufficient to suppress the detection of noise generated artefacts as MLH; 4 min and $120 \mathrm{~m}$ averaging works well for convective layers below $800 \mathrm{~m}$ but more reliable results are achieved with a time averaging interval of at least $10 \mathrm{~min}$.

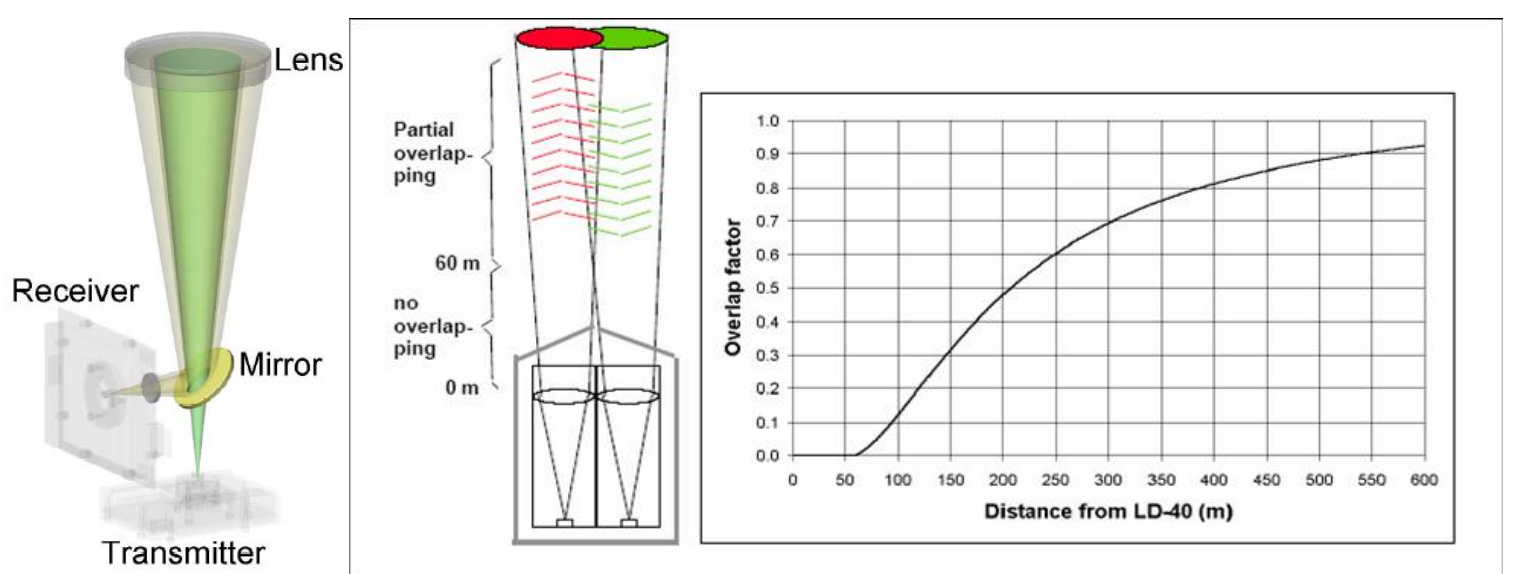

Figure 2. CL31 and LD40 ceilometer schematics

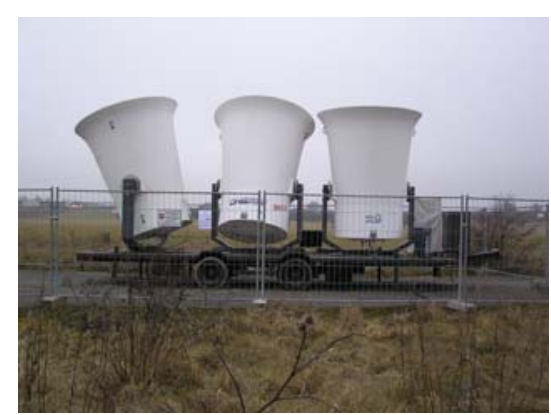

Figure 3. METEK DSDR3x7 sodar. 


\subsection{Sodar}

The sodar (Figure 3) used in this study is a three-antenna METEK DSDR3x7 sodar [14] using an acoustic frequency of $1670 \mathrm{~Hz}$, a height resolution of $30 \mathrm{~m}$, and a maximum range of $1255 \mathrm{~m}$. Two antennas were tilted at 20 degrees zenith angle, the third antenna was looking vertical.

\section{Results}

Some results from the intercomparison period in May 2007 will be displayed here to show the ability of the three remote sensing instruments. Figure 4 presents a comparison of the optical backscatter intensities from the two ceilometers. The largest differences are found in the lower $200 \mathrm{~m}$ close to the ground due to the different optical paths in the two instruments (one optical axis in the CL31 versus two optical axes in the LD40). It turns out, as expected, that the one-lens system (the CL31) is much better suited to investigate the aerosol distribution in the lower layers close to the ground. But also in greater heights some differences can be found, which probably have to be credited to the slightly different wavelengths of the two instruments.
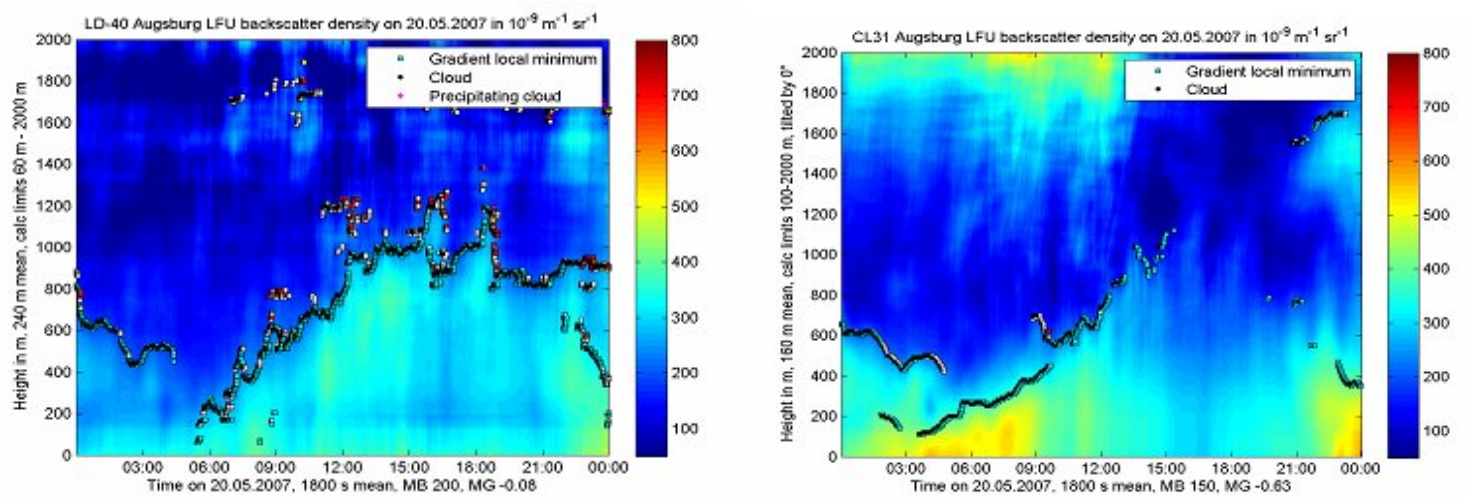

Figure 4. Comparison of optical backscatter intensity for heights up to $2000 \mathrm{~m}$ above ground from the Vaisala LD40 (left) and from the Vaisala CL31 (right) during the intercomparison exercise on 20 May 2007 in Augsburg, Germany.

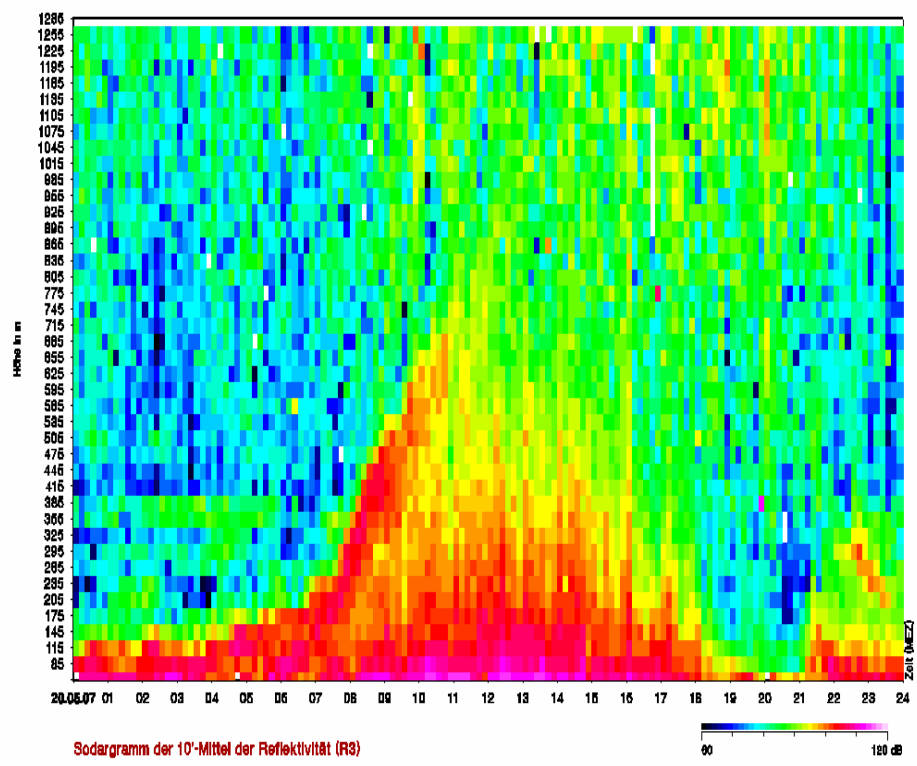

Figure 5. Acoustic backscatter intensity from the METEK DSDR 3x7 sodar for heights up to $1270 \mathrm{~m}$ above ground during the during the intercomparison exercise on 20 May 2007 in Augsburg, Germany. 
Figure 5 displays the acoustic backscatter intensity recorded by the vertical antenna of the sodar. The other two antennas are used together with the vertical antenna in order to measure the threedimensional wind vector from the radial Doppler shifts of the backscattered sound pulses.

In Figure 6 the mixing layer heights derived from the optical data of the two ceilometers are plotted. For large parts of the day both instruments give nearly the same results. In the morning hours it can clearly be seen that the CL31 is much better able to detect the shallow mixing layer height below $200 \mathrm{~m}$. On the other hand, the LD 40 is a little bit better in following the top of the convective boundary layer in the later afternoon.

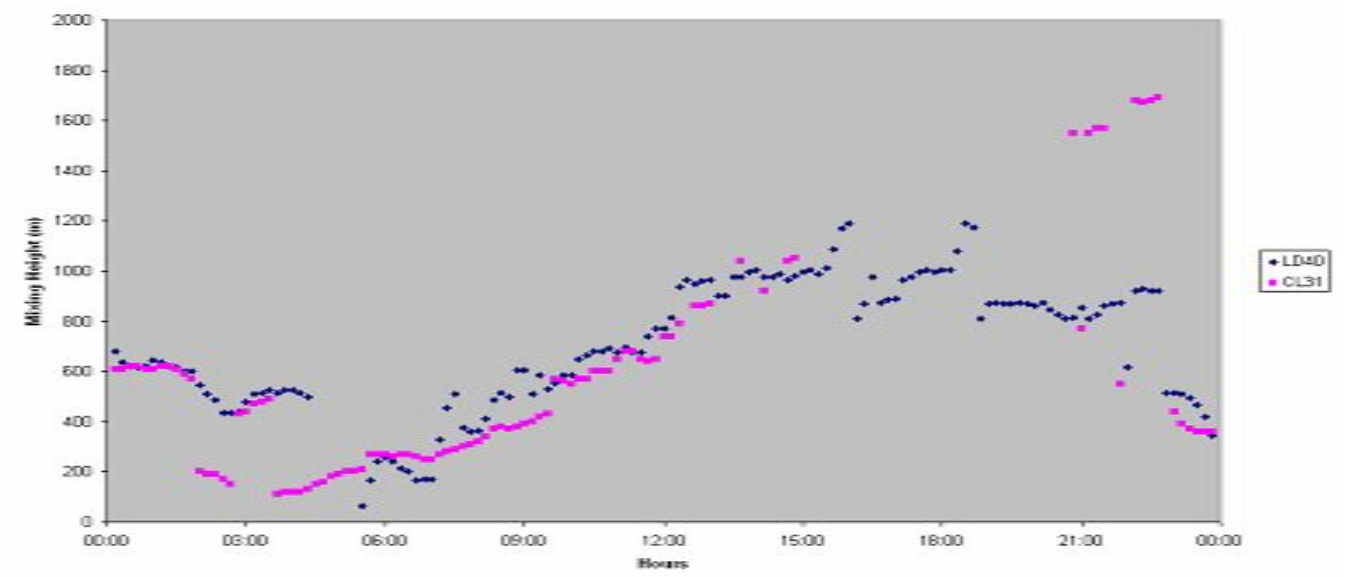

Figure 6. MLH derived from the Vaisala LD40 ceilometer (blue dots) and from the Vaisala CL31 ceilometer (purple dots) during the during the intercomparison exercise on 20 May 2007 in Augsburg, Germany. Sunrise was at 03:31, sunset at 18:56.

In Figure 7 the MLH from the one-lens ceilometer (CL31) and sodar data are compared. Among the plotted sodar data 'top turb.' denotes H1 from eq. (1), 'stable layer' H3 from eq. (3), and 'MLH' $\mathrm{MLH}_{\mathrm{ac}}$ from eq. (4). Among the ceilometer data 'MLH 1' and 'MLH 2' denote the first two H4_n from eq. (7).

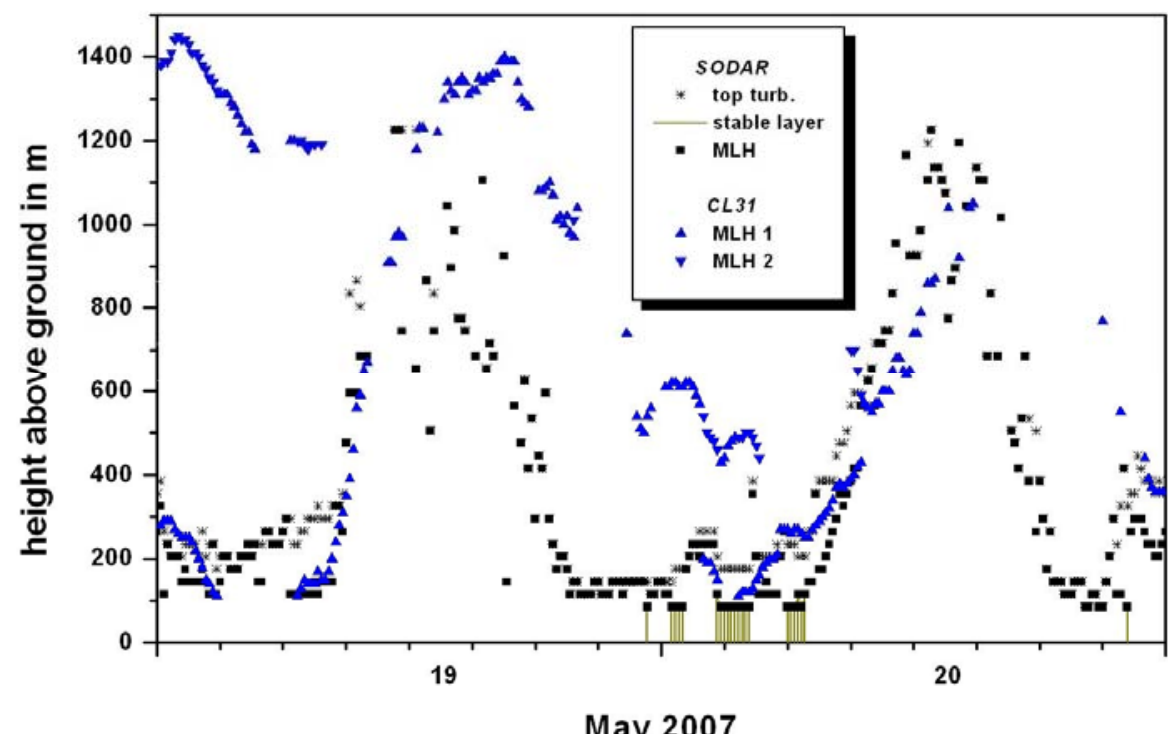

Figure 7. Mixing-layer height in Augsburg, Germany, on 19 and 20 May 2007 from CL31 (triangles) and sodar (Squares, asterisks, and vertical lines) measurements. See text for further details. 
14th International Symposium for the Advancement of Boundary Layer Remote Sensing IOP Publishing IOP Conf. Series: Earth and Environmental Science 1 (2008) 012027 doi:10.1088/1755-1307/1/1/012027

We see that both types of instruments (the acoustic and the optical one) generally give the same results. But there are a few differences which are worth to be looked at in a little more detail.

- On the morning of the first day plotted in Figure 7 two heights are detected by the ceilometer (between 100 and $300 \mathrm{~m}$ and between 1200 and $1400 \mathrm{~m}$ ) while the sodar, due to its maximum vertical range, can only detect the lower one. The layer between these two heights is the residual layer left over from the convective boundary layer of the day before. The same partially happens in the next night (in the centre of the Figure).

- On the second day the rise of the acoustically detected MLH is much faster than the rise of the optically detected MLH. This indicates that the vertical aerosol distribution needs some time to follow the thermal structure of the ABL.

Both facts have already been documented in [2].

\section{Discussion}

Details of the optical construction (one lens versus two lenses) of ceilometers and the choice of the wavelength have some influence on the received optical backscatter intensity. Especially the CL31 ceilometer used in this study has advantages when monitoring shallow nocturnal surface layers and mixing layer heights.

Acoustic remote sensing with sodars allows a good detection of shallow nocturnal mixing layers but sodars have the decisive disadvantage that their vertical range is rather limited. On the other hand, a sodar permits the distinction between stable surface layers, convective boundary layers and the top of turbulent layers.

Acoustic and optical remote sensing mostly deliver complementing results. When they both show the same process, e.g. the start of the development of the convective boundary layer in the morning, they allow the analysis of how fast the vertical aerosol distribution is able to follow the developing thermal structure of the boundary layer.

The intercomparison experiment showed that the intended derivation of spatial structures in the urban mixing layer height over Augsburg will remain difficult from these three instruments used here. For this purpose identical instruments should be used at the different sites. This has been realized in the meantime by substituting the LD40 with a CL31 ceilometer. Results are forthcoming.

\section{Conclusions and Outlook}

Remote sensing with ceilometers and sodars is a good way to monitor the vertical structure of the $\mathrm{ABL}$. These instruments deliver data with high temporal and vertical resolution.

The combined application of acoustic and optical remote sensing allows an assessment of the overall vertical structure of the ABL by indicating the occurrences of nocturnal stable surface layers, convective boundary layers and residual layers.

The comparison of the increase of the height of the convective boundary layer in the morning from acoustic and from optical remote sensing gives some insight in the dynamics of vertical turbulent diffusion in the developing convective boundary layer.

The delay in the development of the vertical aerosol distribution with respect to the development of the thermal structure of the boundary layer is an important result which has to be kept in mind if only ceilometers are used to monitor the mixing layer height.

The deployment of a radio-acoustic sounding system (RASS) could lead to an even more complete monitoring of the structure of the boundary layer since a RASS delivers the temperature profile itself. The then remaining task would be a simultaneous vertical profiling of the moisture content of the boundary layer. But the existing instruments for the measurement of the moisture profile in the atmosphere (Raman-Lidar, water vapour lidar, micro-wave radiometer) still do not have the same vertical resolution and lower range gate which ceilometers and sodar have. 


\section{Acknowledgements}

The measurements in Augsburg were made in cooperation with Jürgen Schnelle-Kreis of the Bayerisches Institut für Angewandte Umweltforschung und -technik (BIFA), Augsburg and Jan Bernkopf of the Bayerisches Landesamt für Umwelt (LfU), Augsburg.

\section{References}

[1] Piringer M, Joffre S, Baklanov A, Christen A, Deserti M, De Ridder K, Emeis S, Mestayer P, Tombrou M, Middleton D, Baumann-Stanzer K, Dandou A, Karppinen A and Burzynski J 2007 The surface energy balance and the mixing height in urban areas - activities and recommendations of COST-Action 715 Bound.-Lay. Meteorol. 124 3-24

[2] Emeis S and Schäfer K 2006 Remote sensing methods to investigate boundary-layer structures relevant to air pollution in cities Bound-Lay. Meteorol. 121 377-85

[3] Schäfer K, Emeis S, Hoffmann H and Jahn C 2006 Influence of mixing layer height upon air pollution in urban and sub-urban areas Meteorol. Z. 15 647-58

[4] Emeis S and Türk M 2004 Frequency distributions of the mixing height over an urban area from SODAR data Meteorol. Z. 13 361-67

[5] Lokoshchenko M A 2002 Long-Term Sodar Observations in Moscow and a New Approach to Potential Mixing Determination by Radiosonde Data J. Atmos. Oceanic Technol. 19 1151-62

[6] Emeis S, Baumann-Stanzer K, Piringer M, Kallistratova M, Kouznetsov R and Yushkov V 2007 Wind and turbulence in the urban boundary layer - analysis from acoustic remote sensing data and fit to analytical relations Meteorol. Z. 16 393-406

[7] Emeis S, Jahn C, Münkel C, Münsterer C and Schäfer K 2007 Multiple atmospheric layering and mixing-layer height in the Inn valley observed by remote sensing Meteorol. Z. 16 415-24

[8] Sarigiannis D A., Soulakellis N, Schäfer K, Tombrou M, Sifakis N I, Assimakopoulos D, Lointier M, Dandou A and Saisana M 2002 ICAROS: An Integrated Computational Environment for the Assimilation of Environmental Data and Models for Urban and Regional Air Quality Int. J. Water, Air, and Soil Pollution: Focus 2 641-54

[9] Beyrich F 1997 Mixing height estimation from sodar data - a critical discussion Atmos. Environ. 31 3941-53

[10] Münkel, C., J. Räsänen, 2004: New optical concept for commercial lidar ceilometers scanning the boundary layer, Proceedings of SPIE, Vol. 5571, 364-74

[11] Schäfer K, Emeis S M, Rauch A, Münkel C and Vogt S 2004 Determination of mixing-layer heights from ceilometer data. In: Remote Sensing of Clouds and the Atmosphere IX, Klaus Schäfer, Adolfo Comeron, Michel Carleer, Richard H. Picard, Nicolas Sifakis (eds.):, Proc. SPIE, Bellingham, WA, USA, 5571 248-259

[12] Schäfer K, Emeis S, Junkermann W and Münkel C 2005 Evaluation of mixing layer height monitoring by ceilometer with SODAR and microlight aircraft measurements. In: Remote Sensing of Clouds and the Atmosphere X, Klaus Schäfer, Adolfo T. Comeron, James R. Slusser, Richard H. Picard, Michel R. Carleer, Nicolaos Sifakis (eds.), Proc. SPIE, Bellingham, WA, USA, 5979, 59791I-1 - 59791I-11

[13] Neff, W.D., R.L. Coulter, 1986: Acoustic remote sensing. In: Lenschow D H (ed.) Probing the Atmospheric Boundary Layer, Amer. Meteor. Soc., Boston, MA, 201-39

[14] Reitebuch $\mathrm{O}$ und Emeis S 1998 SODAR-measurements for atmospheric research and environmental monitoring Meteorol. Z. 7 11-14 